\title{
The Practice of Employability Teamwork Skills
}

\author{
Mohamad Hisyam Mohd. Hashim \\ Faculty of Technical and Vocational Education, Universiti Tun Hussein Onn Malaysia, Parit Raja, Malaysia
}

Email address:

mhisyam@uthm.edu.my

\section{To cite this article:}

Mohamad Hisyam Mohd. Hashim. The Practice of Employability Teamwork Skills. International Journal of Vocational Education and Training Research. Vol. 1, No. 2, 2015, pp. 16-21. doi: 10.11648/j.ijvetr.20150102.11

\begin{abstract}
A soft skill of teamwork is one of the important factors for getting a job. Some technical institutions implemented and embed the soft skill into curriculum. The students have to practice the skills as well on their subject or through specific activities in classroom or outside classroom. The purpose of this research is to identify the practice of technical employability teamwork skill among students of technical institutions. The skills are planning and decision making skill, self-adaptability/flexibility skill, interpersonal relationship skill and communication skill. The quantitative research methodology has been used where questionnaires were used as an instrument to collect the data. This research had involved 226 final semester students in Department of Electrical Engineering. All the data were analyzed using Statistical Package for Social Science (SPSS) to obtain the frequencies, means and standard deviations. The finding showed that the level of teamwork skills is high. The result also show that all the teamwork skills elements are successful been applied by the students. As a whole, this study showed that the technical institutions has enculturation the students on planning and decision making skill, self-adaptability /flexibility skill, interpersonal relationship skill and communication skill.
\end{abstract}

Keywords: Technical, Employability, Teamwork, Technical Student

\section{Introduction}

In Malaysia, the work is an element of virtue for all levels of society to meet the needs of life in the era of globalization. It is a responsibility that needs to be carried by an individual who has entered the realm of work. Once getting hired, is not a simple matter for a person to be committed towards the tasks that has been entrusted to him, and also with the necessary skills and knowledge possessed by them in meeting the needs of the industry. If the individual is not able to use all the skills and knowledge that exists within him, then every tasks given cannot produce high-quality of productivity in which the output of high quality become the core requirement and the main purpose to every industry. Since there is great challenges to get hired today, the employment opportunities only opened to the individuals that been qualified and have the potential to be an excellent worker. However, the increase of the demand for skilful and knowledgeable labour causes a competition among graduate to obtain reasonable place in the employment sector. Thus, the problem of unemployment among graduates arising from the competition impression.

Based on [1], the demand for labor (job vacancy) with labor supply but that the interests of the employer is knowledgeable workforce and are skilful person which not only related to the field of work. The study by [2] found that employers are looking for candidates with the skills like creativity, innate ability, communication, problem solving and teamwork.

Accordingly, the workforce must be established in order to complete the employer's intention to have skills such as good communication skills, ability to make decisions, discipline, dedication, technologically adept and versatile nature. Based on these requirements, certain skills education in producing highly skilled and talented students is an important addition to their academic skills. This is intended skills soft skills which refers to a combination of knowledge, skills and personal characteristics that need to be applied and used by students in their daily lives. This proficiency is essential in meeting the human resources who are competent in the global purposes [3]. The ability of graduates to this skill has received feedback from various parties, especially employers expect graduates are able to perform tasks when employed without any problems.

Soft skills are highly prioritized and required in a job. For someone who mastered these soft skills, he will not only be able to adapt to changes and developments in the sector of employment even facing of everyday life. Soft skills also provide a person act as citizens and workers in the face of rapid technological change and continuous [4]. Thus, in facing of an increasingly challenging job market, graduates today should have particular skills soft skills as demanded by 
employers. Then it becomes the responsibility of the Institute of Higher Education (IHE) to generate graduates who have a balanced and comprehensive expertise in all aspects of intellectual quality or soft skills include attitude, behavior and so on. [5] in his study concluded that at present, local graduates should have elements of soft skills in addition to the academic excellence that can put themselves and compete in the global job market. According to them, the elements of soft skills will enable an employee to use all the knowledge and skills that exist in any occupation. The soft skills include aspects of generic skills identified as a critical element in the global world of work and should be owned by the university graduates. Generally, soft skills is the efficiency or individual ability to master the skills of human nature and relationships with humans and classify elements of soft skills to the seven elements that must be learned student skills include: communication skills, critical skills and problem solving skills, teamwork skills, learning and information management, entrepreneurial skills, ethics and moral professional and leadership skills. However, according [6] have compiled a list of 13 of the most important skills.

Table 1. Engineering Employability Skills developed by Ministry of Higher Education.

\begin{tabular}{ll}
\hline NO. & Skills \\
\hline 1 & Communication Effectively \\
2 & Competent in applications and practice \\
3 & Interpersonal or team working skills \\
4 & Engineering problem Solving and decision making skills \\
5 & Apply knowledge of science and engineering principles \\
6 & Competent in specific engineering disciplines \\
7 & Understand professional, social and t ethical responsibility \\
8 & Lifelong learning \\
9 & Engineering systems approach \\
10 & Knowledge of contemporary issues \\
11 & Design and conduct experiments \\
12 & Skills in theory and research \\
13 & Entrepreneurial skills \\
\hline
\end{tabular}

(Ssource: The Future of Engineering Education In Malaysia, 2007; EAC Manual, 2003; ABET, USA (1998)

Based on Table 1, a student who graduated in engineering program such as mechanical, civil, electrical and electronic should be practiced the those skills in order to strengthen their skill especially in industrial organization. The objective of this research is to identify the level of practices on employability teamwork skills.

\section{Literature Review}

Soft skill is a non-technical skills that are essential to produce individuals who have the skills themselves and be competitive in the self development, personality and everyday life of students nationally or internationally. In personal development of students, the ratio of soft skills should be given priority and attention it deserves in line with the national vision to produce human excellence, glory and distinction. Generally, soft skills can be defined in various interpretations and it does not have a specific meaning and proper. This can be evidenced through soft skills terminology used in each country is different even though the goals and characteristics that practice is almost the same. Them in the United States the term necessary skills, employability skills, or workplace know-how has been used. New Zealand also have used the term essential skills while in Australia the term used is the key competencies, soft skills, or employable skills. For the United Kingdom the term key skills or core skills in use [7].

Among the elements identified as critical in the global world of work and be possessed by graduates of the Institute of Higher Education (IHE) is the soft skills that cover generic skills. This was supported by the [8] also noted that soft skills are important because the industry's needs today is more geared to the ability, initiative and flexibility in handling multiple tasks given.

Along with the development of soft skills in the era of globalization, a variety of studies leading to the extent of development and the importance of soft skills elements themselves have been done. Even in Malaysia alone, this study is considered very important, especially in the country's efforts to achieve Vision 2020, particularly in the field of technical education and vocational training (TEVT). This is because these soft skills have become one of the important and vital in the education system to improve and enhance the quality of training on the overall skill level of the workforce in line with the development of industrial training. TEVT aims to increase the supply of skilled human capital in Malaysia by providing quality education to students who have the aptitude and ability in technical and vocational fields. Education sector aims to provide skills that can be used immediately in the job market. TEVT into mainstream education option in most developed countries.

According to [9], suggesting that most employers now look to the individual attributes and soft skills themselves in basic factor recruitment. Moreover, he also stated that the education should also seek or maintain their relationship with industry in order to produce graduates who can meet the needs of personal attributes, values and attitudes required by employers, and not only adjust the valuation methods and learning. From the feedback given is generally known that the industry demand for the soft skills are at a high level and there among the educators who argue that different soft skills required by employers according to the level of employment. It can be stated here that the soft skills become an important element in the employment sector at present.

Each sector in education including pre-school, primary school, secondary school, and also institute of Higher Education (IHE) has a role in helping students to awaken their soft skills proficiency. This proficiency can be woken through individual's life, and also in various ways which included the nature of work and life in an educational context. Between proficiency of soft skills that need to be owned by the workers and the workers to be which are, proficiency in reading, writing and computers, oral communication and listening skills with impressive, skill in critical thinking and problem solving, maintenance personnel with confidence and power 
businesses, finesse interpersonal, leadership memorable, work in the collection and have knowledge of the principles of technology [10]. Based on the definitions of the term and interest otherwise it can be seen that the soft skills is a skill that needs to be owned by an employee regardless of job and employment sectors that are or will be involved. These skills are of a general nature and variety and do not refer specifically to the relevant technical skills. However, soft skills are specifically referring to the specific skills required by the employee or prospective employee. So, prospective graduates who will enter the industrial sector should be concerned about these skills and need to be applied in the students while in the education sector so that the skills can be improved before it is in the nature of jobs in the future.

In Institute of Higher Education (IHE) in Malaysia, elements of soft skills were determined based on expert opinion, research and experience of the institution that has done so. Seven key elements have been implemented in all institutes of higher education include communication skills, critical thinking and problem solving skills, teamwork skills, learning and information management, entrepreneurial skills, professional ethics and moral and leadership skills.

Ministry of Higher Education (2006) has showed the model for seven elements of soft skills that have been determined to be implemented in Institutions of Higher Education (IHE), which include communication skills, critical thinking and problem solving skills, teamwork skills, continuous learning and management information, entrepreneurial skills, professional ethics and moral and leadership skills.

\section{Methodology}

Quantitative research methodology has been used in this research which questionnaire is main instrument and was analysed using descriptive tools. Descriptive refers writing that describes a situation or factual situation systematically and accurately ([11]. According to [12], in educational research, questionnaires has been used as tool to get the right information and resources relevant facts, beliefs, feelings and so on. Therefore, questionnaires is the most appropriate method of data collection and make the data analysis easy to do compared with direct observation method that takes a long time.

This design was chosen because it is well suited to identify the application of soft skills, teamwork skills that exist within the Polytechnic students in engineering. This is because, according to [13] stated that a survey is used to obtain information from respondents either hundreds or thousands of respondents. This type of design is compatible with the goal of researchers to look teamwork skills students where the survey was done among diploma of engineering students in their final semester at the institutions. Data were collected through questionnaires. This study was conducted in three department of electrical engineering of technical institutions.

\subsection{Populations, Sampling and Collecting Data}

Before the sample selection is made, it is important to identify population to be examined. The population may be defined as a set of characteristics show a certain perception or size up a collection of individuals or objects. This may be explained by [14] states the study population mean a collection of individuals who represent the same criteria with the aim of the study being undertaken. They will be identified between the groups to be studied and so on are used by investigators to obtain and collect data for purposes of analyzing the study.

The sample also is a sub set than the population targeted by the investigators, and adaptive assessment carried onto the sample is able to represent the whole population. [15] The sample is the source for the data. Through sampling, investigator should get intimation of something populations by questioning half of the members of that population [16]. Then the sample was selected over-sampling process study population.

Random sampling method was used in the study which involved engineering students in technical Institution. The selected sample was final semester students of Department of Electrical Engineering in 3 (three) technical Institutions. They were selected because they will go to do industrial training and will be worked after graduation. Therefore, some of them were involved on the research as a respondent. The total population and the respondent for this study are shown in Table 2:

Table 2. Institution, population and respondent.

\begin{tabular}{lll}
\hline Technical Institution & population & respondent \\
\hline A & 35 & 32 \\
B & 279 & 162 \\
C & 97 & 80 \\
Total & 411 & 274 \\
\hline
\end{tabular}

To ensure the effectiveness of this research, researcher will provide questionnaires and data collection will be conducted in three selected polytechnic. A questionnaire will be distributed to students in their final semester in diploma (sem 6) in the Department of Electrical Engineering. This data collection session will be distributed and controlled by the researcher, in this way, researchers can communicate directly with the respondent that there might be any setbacks towards items provided. Apart from this, this method can save time in the process of gathering and they can ensure that all questionnaires were distributed to fully reassemble in a short time. The data collected will be analyzed to make the findings.

In this study, a tool or instrument used was a set of questionnaires designed to obtain feedback from respondents. It is an instrument commonly used in descriptive studies. The questionnaire is more efficient and suitable for use especially in large populations. In addition, it is also used to get all information about the facts, beliefs, feelings, desires, and others.

Construction of the questionnaire was conducted is based on a number of matters that have been tabled namely: $i$. Respondent can read and understand the items in question inquired well. ii. Respondent have sufficient knowledge and experience to answer the items in question searchingly, iii. 
Respondent voluntarily and willingly answered questions inquired. Researcher developed a set of questionnaires which consist 2 part. Part A of was refer to respondent background and part B was questions regarding the level of application of teamwork skill of teamwork skills.

Part A covers the demographic data of respondents who use multiple-choice questions in the background collecting data respondents. Demographic data used in the study of differences by demographic variables. Part B questionnaire using Likert scale was formed involving the application and elements teamwork skills in students. Table 3 show the two part of questionnaire.

Table 3. Questions for Part $A$ and $B$.

\begin{tabular}{|c|c|c|}
\hline Part & Question & Item \\
\hline & & Gender, age, place of study at the \\
\hline dons) & $\begin{array}{l}\text { und } \\
\text { as }\end{array}$ & $\begin{array}{l}\text { ns. } \\
\text { s, namely }\end{array}$ \\
\hline $\begin{array}{l}\text { part B (40 } \\
\text { questions) }\end{array}$ & $\begin{array}{l}\text { regarding the } \\
\text { level of } \\
\text { application of } \\
\text { teamwork skills }\end{array}$ & $\begin{array}{l}\text { the skills of planning and decision } \\
\text { making skills, self adaptability / } \\
\text { flexibility, interpersonal relationship } \\
\text { and communication skills. }\end{array}$ \\
\hline
\end{tabular}

This study aims to ensure the accuracy of the items in the questionnaire from the aspect of validity and reliability before the exact research. A pilot study is one of the most important activities for each survey in which they determine the validity and reliability of the instrument and to test the best method of administering the instrument, known samples and methods of analysis. Therefore, before the actual study was conducted, the pilot study should be conducted to ensure that the instrument used in this study has validity and reliability. This study also aimed to get an overall picture about the quality of the questionnaire. In addition, it also aims to verify the content in terms of format, language, writing, objectives, directions and spelling and reliability questions.

This study using Cronbach alpha value as the value exceeds 0.6 Reliability for items inquired about. Alpha coefficients maximum value is 1 . If only the alpha value less than 0.6 coefficients, the instruments used in the study had a low Reliability. Cronbach Alpha Reliability is the stage of the items that fostered Questions. Reliability something items are high with Cronbach alpha values in excess of 0.6 and the maximum value is 1 . Likert scales were used in answering the questionnaire Part B in assessing the level of implementation of the respondents in teamwork skills. In this study, using a Likert scale used five scale measurement starts with a score of 5 representing strongly agree, 4 and 3 are agreeing to disagree. While the second represents not agree and 1 is strongly disagree. Table 4 is show the element and item of teamwork skill.

A questionnaire is a form contains questions and spaces to answer to where a sample form used for all respondents. It can only be established by objective research to collect data. There are two advantages in using a questionnaire which each respondent was asked the same question. Thus, researchers can make a comparison between a respondent to another respondent.
Thus, the data collected will be easier to be processed by computer. Another benefit is that this method will accelerate the task of gathering data and ensure the quality of the data collected is quality.

Table 4. Elements and items of teamwork skills.

\begin{tabular}{lrl}
\hline $\begin{array}{l}\text { Elements of teamwork } \\
\text { skills }\end{array}$ & Items \\
\hline & i. & Identifying problem \\
Planning and decision & ii. & Collecting information \\
making skills & iii. & Evaluating information \\
& iv. & Sharing information \\
& v. & Setting goals \\
& i. & Become an assistant to other members \\
flexibility & ii. & Cooperation in dividing tasks \\
& iii. & Give and receive any feedback \\
& iv. & Monitor potential \\
Interpersonal & i. & Sharing tasks \\
relationship skills & ii. & Finding mutually agreed solution \\
& iii. & Considering various ways of doing tasks \\
& iv. & Managing / influence dispute \\
& i. & Prepared accurate and clear information \\
ii. & Listening well \\
iii. & Asking questions \\
iv. & v. & Open minded in sharing ideas \\
& & observe the body language of others \\
\hline
\end{tabular}

\subsection{Validity and Reliability}

Validity and reliability analysis was conducted before the actual study conducted on respondents to assess the reliability of each item is tested before the actual item distributed. Validity was carried out with reference to the five lecturers from the Faculty of Technical and Vocational Education, UTHM to evaluate the questionnaire constructed and the validity of the expert is of the language, presentation and content of the questionnaire. Whereas the purpose of the actual questionnaire reliability analysis was conducted using SPSS (Statistical Package for Social Science) version 21.0 was to get the characteristics of consistency for all the answers to the questionnaires distributed to groups that have been sampled.

Before the exact research, the researchers conducted a pilot study involving 30 respondents were randomly selected from among the students in their final semester in diploma in the Department of Electrical Engineering. Students who are selected to participate in this pilot study has features in common with the actual respondents, namely the end of the semester students majoring in electrical engineering for the diploma program. Reliability index results for each ratio shown in Table 5 demonstrate good reliability indices for the questionnaire given to student, which shows the results of the index with a value of 0.863 and 0.883 respectively. While the indices of interpersonal relationship skills and communication skills are 0.865 and 0.850 . 
Table 5. Index of application reliability teamwork skills students.

\begin{tabular}{lll}
\hline No & Aspect & Reliability Index \\
\hline 1 & Planning and decision making skills & 0.863 \\
2 & Skills self adaptability / flexibility & 0.883 \\
3 & Interpersonal relationship skills & 0.865 \\
4 & Communication Skills & 0.850 \\
\hline
\end{tabular}

The quantitative data obtained from the questionnaires were analyzed by descriptive statistics using SPSS Statistical Package for the Social Sciences version 21 (SPSS 21) to accommodate a lot of data analysis and repeated more efficiently and quickly. The purpose of this software is to find the frequency, percentage and mean of data obtained. Inferential statistical method t-test and ANOVA were used. Therefore, the use of this software is compatible with all the necessary elements in this study. To achieve the objective of assessing level of implementation of teamwork skills in engineering students at the Polytechnic from the aspects of planning skills and decision making skills, self-adaptability / flexibility, interpersonal relationship and communication skills, researcher using descriptive statistics of the score mean and standard deviation. Mean is the average obtained by adding all the scores and divide by the number of respondents or item. This value describes the tendency of each variable on average. Analysis of the mean will follow the schedule Determination of Levels Mean Score which ranges mean score indicating the level of interpretation of the score as a guide for the results of the study.

\section{Findings}

To answer the research question, there are four aspects to know the level of teamwork skills. The skills are: planning and decision-making skills, self-adaptability / flexible, interpersonal relationship and communication skills.

\subsection{Planning and Decision-making Skills (PDM)}

PDM is a skill which will be given opportunities for technical peoples like engineer and technologist to plan and made decision as well. 10 items of the skills has been asked is showed in Table 6 below.

Table 6. Planning and decision making skills.

\begin{tabular}{lll}
\hline No & Items & Mean \\
\hline 1 & Help identify the problems faced. & 4.38 \\
2 & Teach to gather information in making decisions. & 4.39 \\
3 & Encouraged more sensitive to the problems faced. & 4.45 \\
4 & Train to analyze the problems encountered. & 4.42 \\
5 & Eencouraged to give opinions to solve problems. & 4.38 \\
6 & Train do recommendations to solve the problem. & 4.50 \\
7 & Helped to set goals & 4.42 \\
8 & Help identify the impact of their decisions. & 4.40 \\
9 & Teach to assess the quality of the decisions have been & 4.44 \\
10 & made. & 4.48 \\
Overall Mean & 4.43 \\
\hline
\end{tabular}

Table 6 show that the institution has trained students to analyse the problem is highly (4.50), compare to encourage them to give opinions to solve problem (4.38). However, overall finding on planning and decision skill is high (4.43).

\subsection{Self Adaptability (SA)}

SA is able or willing to change in order to suit difference conditions. 10 items of the skills has been asked is showed in Table 7 below. SA is very important in an organization especially in industrial. Therefore, the technical Institution should be design their curriculum and instruction as well in order to achieve the objective of technical institution where it related to industry. The ability of design the best curriculum for technical students will be decreased if they have not expert on instructional design in technical and vocational education. In the teaching and learning process, the lecturer should be creative on developing of instruction in class. Some teamwork projects must be implemented during the instruction. This study that to try to understand the skills of self-adaptability among the students will be increased the knowledgeable of instructional design.

Table 7. Self-adaptability / flexibility Skills.

\begin{tabular}{lll}
\hline No & Items & Mean \\
\hline 1 & Train to share information in group & 4.39 \\
2 & $\begin{array}{l}\text { Nourish the commitment attitude in solving problems } \\
\text { Trained to give the best alternative to solve the }\end{array}$ & 4.36 \\
3 & $\begin{array}{l}\text { problem. } \\
\text { Encourage to inspire other group members }\end{array}$ & 4.39 \\
4 & $\begin{array}{l}\text { Help give opinions to improve the performance of } \\
\text { group members }\end{array}$ & 4.39 \\
& $\begin{array}{l}\text { Train to manage the distinction conflicts among group } \\
\text { members. }\end{array}$ & 4.38 \\
7 & $\begin{array}{l}\text { Encouraged to control myself from any unwelcome } \\
\text { behavior. }\end{array}$ & 4.35 \\
8 & $\begin{array}{l}\text { Train to teach the group members in problem solving } \\
\text { Encourage to cooperatee in solve the problem with }\end{array}$ & 4.39 \\
group members. & 4.48 \\
10 & $\begin{array}{l}\text { Train to make decision after having group discussion } \\
\text { Overall Mean }\end{array}$ & 4.54 \\
\hline
\end{tabular}

Table 7 show the institutions had trained students the self-adaptability skills. However, item train me to make decision after having group discussion is higher score (4.54) and item encouraged to control myself from any unwelcome behaviour is low.

\subsection{Interpersonal Relationship (IR)}

IR is referred as connection with relationships between people. The 10 items of the skills has been asked is showed in Table 8 below.

Table 8. Interpersonal relationship skills.

\begin{tabular}{lll}
\hline No & Items & Mean \\
\hline 1 & Train to cooperate in the collection & 4.41 \\
2 & $\begin{array}{l}\text { Nourish to appreciate every initiative to foster team } \\
\text { members in solving problems. }\end{array}$ & 4.35 \\
3 & Improve focus during group discussions. & 4.33 \\
4 & Help to adapt with the task given & 4.38 \\
5 & Help to understand with the task given & 4.40 \\
6 & $\begin{array}{l}\text { Eencourage to be open minded towards feedback given } \\
\text { by members of the group }\end{array}$ & 4.42 \\
\hline
\end{tabular}




\begin{tabular}{lll}
\hline No & Items & Mean \\
\hline 7 & Train to give suggestion for the group members & 4.43 \\
8 & Train to be creative thinking in group discussion & 4.38 \\
9 & Help to evaluate myself in group & 4.47 \\
10 & Teach to be responsible in group & 4.51 \\
Overall Mean & 4.41 \\
\hline
\end{tabular}

Table 8 show that the score mean of IR is high (4.41). However, some item "improve focus during group discussion" is low compare to other items.

\subsection{Communication (C)}

Communication is act of communicating with people. In a team working, communication is compulsory. In the technical institution, the student involved in activities rather in classroom or outside would be assisted them to enhance the communication skill. A research has been done to analyse mean of the item and the result are showed in Table 9 below.

Table 9. Communication skills.

\begin{tabular}{lll}
\hline No & Items & Mean \\
\hline 1 & Train with proper intimation spread & 4.42 \\
2 & Assist to describe an idea clearly & 4.37 \\
3 & Improved ability to be a good listener & 4.42 \\
4 & Ttrain in conveying information clearly & 4.46 \\
5 & Help to interact clearly with group members & 4.42 \\
6 & Encouraged to ask questions to the members of the & 4.42 \\
7 & group & 4.47 \\
8 & Encouraged to be open minded while sharing ideas with & 4.42 \\
9 & Train to give constructive ideas to group members & 4.42 \\
10 & Train to attract attention of team members during & 4.51 \\
Overall Mean & 4.43 \\
\hline
\end{tabular}

Table 9 show that the score mean of IR is high (4.43). However, some item "assist to describe an idea clearly" is low compare to other items and Encourage the group members to give suggestions is high.

\subsection{Conclusion}

The level of practice on technical employability teamwork skills among students at the institutions is high. It means that the institution has practiced the planning and decision making skills, self-adaptability /flexibility skill, interpersonal relationship and communication skills in learning and teaching process or they have created the culture to students.

\section{Acknowledgements}

Many people contributed immensely to the success of this article. I am grateful to all the students who are participated in this study for their effort. I appreciate the organizers of World Conference on Technical and Vocational Education and Training (2014). My thanks go to anybody who in diverse ways contributed to the success of this paper.

\section{References}

[1] Ministry of Higher Education (2006). Soft Skill development Module for Institution of Higher Leraning, Malaysia. Serdang, Selangor: Publisher: Universiti Putra Malaysia.

[2] ACNielsen Research Services (2000). Employer Satisfaction With Graduate Skills. Australia: Research Report Evaluations and Investigations Programme Higher Education.

[3] Adnan, N.A. (2004). Generic Skills Profile Technical Stream Students in Polytechnic. Kolej Universiti Tun Hussein Onn: Unpublished Master Thesis.

[4] Syed Jaafar, S.N.A. (2002). Generic Skill to Meet the needs of the Job Market: Survey Among Students of Engineering Diploma at the Final Semester. Kolej Universiti Tun Hussein onn: Unpublished Master Thesis

[5] Nordin, M.S. \& Mohd Tahir, K.(2004). Generic Skill-The Importance of the Current Employer Requirment. Universiti Teknologi Malaysia.

[6] Hassan,B., Mohd Zaidi, O., Zainal, M., Abang Abdullah, A.A., Badrulhisham,A.A, Abdul Hamid, H, Nik Abdullah, N.M, Azmi, H, \& Zaidi, M.R., (2007). The Future of Engineering Education in Malaysia. Ministry of Higher Education, Malaysia:Department of Institutions of Higher Education Management.

[7] Clayton, B. (2012) Keeping Current: The Industry Knowledge and Skills of Australian TVET Teachers. Proc. of the 2nd UPI International Conference on Technical and Vocational Education and Training. Indonesia: Bandung.

[8] National Centre of Vocational Education Research (2003). At a Glance: Defining Generic Skills, National Center for Vocational Education Research. Australia: Australia National Training Authority

[9] Arshad, N.H. (2007). Generic Skills among students in the needs of industry. UTHM: Unpublished Master Thesis

[10] Imel, S. (1999). New views of adults learning. Trends and Issues Alert No. 5. Education Resources Information Center (ERIC). Retrieved 15 Disember 2014 from http://www.calpro-online.org/eric/docs/tia00073.pdf

[11] Ghafar, M. N. A. (1999). Education Research : Publisher: Universiti Teknologi Malaysia.

[12] Hashim, S. \& Sidi, F. (2010). The Perception of the final semester Students Against the Application pf SPH 4 Enterpreneurial Skills. Pg. 1-9 (unpublished)

[13] Ibrahim Mukhtar, M., Roddin, R., \& Ahmad Sapawi, A. (2008) Technical and Vocational Education in the Aboriginal Community. National Seminar on Teacher Education Cordinating Commitee (JPPG 2008), 13-15 December 2008, Bayview Hotel, Langkawi, Malaysia.

[14] Creswell, J. W. (2003). Research Design: Qualitative, Quantitative, and Mixed Method Approaches. $2^{\text {nd }}$ ed. Thousand Oaks, California: Sage Publications.

[15] Abdul Latif, A. \& Abu Hanifah, A. (2010). Command of English Among the Students Life Skills PKPG. Skudai: UniversitiTeknologi Malaysia. pp. 1-13. (Unpublished)

[16] Ghafar, M. N. A (2003). Design Educational questionare Survey: Publisher Universiti Teknologi Malaysia. 